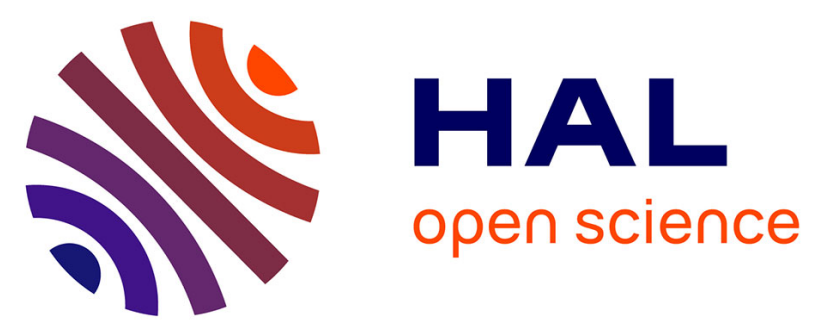

\title{
The HLA-G low expressor genotype is associated with protection against bipolar disorder.
}

\author{
Monojit Debnath, Marc Busson, Stéphane Jamain, Bruno Etain, Nora \\ Hamdani, Hélène Moins-Teisserenc, Wahid Boukouaci, Mohamed Lajnef, \\ Djaouida Bengoufa, Alain Malafosse, et al.
}

\section{To cite this version:}

Monojit Debnath, Marc Busson, Stéphane Jamain, Bruno Etain, Nora Hamdani, et al.. The HLA-G low expressor genotype is associated with protection against bipolar disorder.. Human Immunology, 2013, 74 (5), pp.593-7. 10.1016/j.humimm.2012.11.032 . inserm-00864639

\section{HAL Id: inserm-00864639 https://www.hal.inserm.fr/inserm-00864639}

Submitted on 23 Sep 2013

HAL is a multi-disciplinary open access archive for the deposit and dissemination of scientific research documents, whether they are published or not. The documents may come from teaching and research institutions in France or abroad, or from public or private research centers.
L'archive ouverte pluridisciplinaire HAL, est destinée au dépôt et à la diffusion de documents scientifiques de niveau recherche, publiés ou non, émanant des établissements d'enseignement et de recherche français ou étrangers, des laboratoires publics ou privés. 


\section{The HLA-G low expressor genotype confers protection}

against Bipolar Disorder

Monojit Debnath ${ }^{1,2}$, Marc Busson ${ }^{1,3,7}$, Stéphane Jamain ${ }^{2,4,5,6}$, Bruno Etain 2,4,5,6, Nora Hamdani ${ }^{2,4,5,6}$, Hélène Moins-Teisserenc ${ }^{1,3,6,7}$, Wahid Boukouaci ${ }^{1,3,7}$, Mohamed Lajnef ${ }^{2,4,5,6}$, Djaouida Bengoufa ${ }^{3}$, Alain Malafosse ${ }^{8}$, Frank Bellivier ${ }^{2,4,5,6}$, Chantal Henry ${ }^{2,4,5,6}$ Jean-Pierre Kahn ${ }^{10}$, Rajagopal Krishnamoorthy ${ }^{1,6,9}$, Dominique Charron ${ }^{1,3,6,7}$, Marion Leboyer ${ }^{2,4,5,6}$ and Ryad Tamouza $* 1,3,6,7$

1. INSERM, UMRS 940, Hôpital Saint Louis, Paris, F75010, France.

2. INSERM, U 955, IMRB, Psychiatrie Genetique, Créteil 94000, France.

3. Laboratoire Jean Dausset, Hôpital Saint Louis, Paris, F75010, France.

4. Université Paris-Est -Créteil, Faculté de Medecine, Créteil, 94000, France

5. AP-HP, Pôle de Psychiatrie, groupe hospitalier Henri Mondor, Créteil F-94000, France.

6. Fondation FondaMental, Créteil, France.

7 . Univ Paris Diderot, Sorbonne Paris, cité, France.

8. Département de Psychiatrie, Université de Genève, Genève, CH-1205, Suisse.

9. INSERM, U 763, Robert Debré Hospital, Paris, Paris F-7519, France.

10. Service de Psychiatrie et Psychologie Clinique, CHU de Nancy, Hôpitaux de Brabois, F54500 Vandoeuvre Les Nancy, France.

*Address for correspondence: Dr Ryad Tamouza. Laboratoire Jean Dausset Hôpital Saint Louis. 1, avenue Claude Vellefaux, 75010 Paris, France. Phone: 33142494890. Fax: 331424946 41. E-mail: ryadtamouza@yahoo.fr

Conflict of Interest Statement: All authors declare that there are no conflicts of interest. 


\begin{abstract}
Objectives: Implication of immune processes such as inflammation and autoimmunity in bipolar disorder (BD) has recently gained increasing attention. Tolerogenic molecules, among which HLA-G plays a prominent role, mediate the modulation of such processes. The HLA-G locus is characterized by a number of polymorphisms in the non-coding regions including a functionally relevant 14 base pair (bp) insertion/deletion (Ins/Del) allele affecting the HLA-G expression. We postulate that genetically determined functional differences in immune modulation may contribute to immune dysregulation observed in BD.
\end{abstract}

Methods: to explore this possibility we analysed genomic DNAs from 561 BD patients and 161 healthy controls for the HLA-G 14bp Ins/Del dimorphism using a polymerase chain reaction-based assay. Genetic associations with $\mathrm{BD}$ as well as relationship with demographic and/or clinical variables were examined using Chi-square testing.

Results: we found that the HLA-G 14bp Ins/Ins genotype was significantly more prevalent in healthy controls than in BD patients (HLA-G 14bp Ins/Ins vs other genotypes: $22 \%$ vs $14 \%, p$ $=0.016$, corrected $p(p c)=0.032)$. Subsequent analysis, after stratification of patients based on their season of birth, revealed that the prevalence of the protective HLA-G $14 \mathrm{bp}$ Ins/Ins genotype is lower among patients born during the winter season as compared to those born in other periods (HLA-G 14bp Ins/Ins vs the other genotypes: $6 \%$ vs 17\%, $p=0.003, p c=0.006$ ).

Conclusion: possible mechanisms between low HLA G expression and resistance to infections as well as potential relationships between infections in early life and susceptibility to BD are discussed. 


\section{Key words}

Bipolar disorders

HLA-G

Polymorphism

Immune modulation

Seasonality of birth 


\section{Introduction}

Bipolar disorder (BD) is a common severe mental illness ranked as the $4^{\text {th }}$ leading cause of disability, affecting 1 to $4 \%$ of the population worldwide (Collins et al., 2011). Although the pathogenic mechanism remains elusive, BD is recognized as a multifactorial disorder involving interactions between multiple genetic and environmental factors (Serretti at al., 2008; Lichtenstein et al., Lancet, 2009). The reported heritability ranges from 60 to $85 \%$ indicating that genetic factors are important in the etiopathology of the disorder (Farmer, Elkin and McGuffin, 2007) while the significance of environmental factors is highlighted by a concordance rate of only 40 to $70 \%$ among monozygotic twins (Taylor, Faraone and Tusang, 2002). Moreover, patients with bipolar disorder show excess of winter births (5.8\%) possibly associated with early-life environmental infective insult (Moore et al., 2001). Further accumulating evidence pinpoints towards an immunological substratum encompassing both the innate and adaptive immunity in the etiopathology of BD (for review see Goldstein et al., 2009 and Hamdani et al., 2011). Indeed, the existence of a chronic low-grade inflammation in BD patients both during acute episodes and euthymia is evidenced by the elevated plasma levels of various proinflammatory factors (reviewed in Goldstein et al., 2009). Although no specific gene influencing immune dysregulation in $\mathrm{BD}$ has been identified, genetic association between a TNF alpha promoter variant and mood disorders including BD that range from clinical conditions close to symptoms of depression ("vital exhaustion" syndrome) to late life depression and BD has been reported (Blume et al., 2010; Clerici et al., 2009; Czerski et al., 2008). Such immune dysfunction is further strengthened by the preferential association of $\mathrm{BD}$ with organ-specific auto-immunity, in particular thyroiditis (Padmos et al., 2004; Vonk et al., 2007; Eaton et al., 2010). Potential contribution of infections in the pathogenesis of BD is exemplified by the association between Borna and Herpes simplex virus infections and the incidence rate of BD incidence rate (Terayama et al., 2003; Dickerson 
et al., 2004), although recently contested concerning Borna virus (Hornig et al., 2012). In addition, genome-wide association studies (GWAS) demonstrated a significant genetic association of the major histocompatibility complex (MHC) regions with BD (Purcell et al., 2009; Figueiredo and Mendes de Oliveira, 2011). Altogether these findings raise the possibility that impaired immune regulation could be central to the pathogenesis of $\mathrm{BD}$, at least in a subset of BD patients and common genetic variations in the immune regulatory genes of the MHC region may be associated with the genetic susceptibility to and/ or resistance against $\mathrm{BD}$.

Among the pivotal modulators of immune function, the human leukocyte antigen-G (HLAG) molecules are of particular interest because of their various immunosuppressive/immune tolerogenic properties (Rouas-Freiss et al., 1997; Wiendl et al., 2002; Bainbridge et al., 2000). Belonging to the non-classical HLA-class Ib family and encoded by a locus mapped telomeric to HLA-A gene, the HLA-G molecules are structurally similar to their HLA classical counterparts, yet are distinct by their limited tissue distribution in physiological conditions, diversity of their protein isoforms [membrane-bound and soluble isoforms (sHLA-G)] and a unique pattern of polymorphisms in the non-coding regions especially within the promoter and the 3'-untranslated regions (3'UTR) (Paul et al., 2000, Larsen and Hviid, 2009). As identified to date, HLA-G gene presents a limited number of exonic polymorphisms with 46 alleles accounting for 15 protein variants (IMGT/HLA sequence database). Each of these alleles bears either a 14-base pair (bp) insertion (Ins) or deletion (Del) polymorphism in the 3'UTR that influences the HLA-G expression. Indeed, the 14bp Ins allele was demonstrated to be associated with low levels of both HLA-G mRNA and circulating sHLA-G isoforms (Chen et al., 2008; Rizzo et al., 2008) and hence we denominated it as "low expressor" allele (Boukouaci et al., 2011 in press). Reduced expression of HLA-G has been predicted to compromise the efficacy of the process of immune tolerance. 
Disease association studies implicating the HLA-G locus included a variety of clinical entities viz gestational complications, auto-immunity, infections, cancers and solid organ transplantation (Larsen and Hviid, 2009). But, to our knowledge, its potential implication in psychiatric disorders has not been explored so far. Given the immune dysfunctional phenotypes of $\mathrm{BD}$, we investigated, in a case/control study, if the functionally relevant $14 \mathrm{bp}$ dimorphism of the HLA-G gene is associated with BD.

\section{Materials and Methods:}

\subsection{Subjects}

Five hundred and sixty-one BD patients meeting DSM-IV criteria (A.P.A. 1994) for BD (type I or II), consecutively admitted to three French university-affiliated psychiatry departments (Paris-Créteil, Bordeaux and Nancy), were interviewed by trained psychiatrists, using the French version of the Diagnostic Interview for Genetic Studies (DIGS version 3.0) (Nurnberger et al., 1994). All patients were euthymic at inclusion (i.e. having a MontgomeryAsberg Depression Rating Scale (Montgomery and Asberg, 1979) score and a Mania Rating Scale (Bech et al., 1978) score no more than five. A set of demographic and/or clinical variables (Table 1) was taken into account and recorded while diagnosing the patients. One hundred and sixty-one ethnically matched healthy controls were recruited from blood donors at the Pitié-Salpêtrière and Henri Mondor Hospitals (France) and controls interviewed with the DIGS for personal history of psychiatric disorders and about family history using the National Institute for Mental Health Family Interview for Genetic Studies (Maxwell 1992). Only those, with neither personal nor family history (first degree) of psychiatric disorders, affective disorders or suicidal behavior were included. All patients and controls were of French descent, with at least three grandparents from mainland France. Written informed consent was obtained from all participating subjects and the institutional ethical committee 
approved the research protocol.

\subsection{HLA-G genotyping}

Genomic DNA was extracted from EDTA-treated peripheral blood samples using the standard salting out procedure (John et al., 1991). The 14-bp Ins/Del polymorphism (rs66554220) in the exon 8 encoding the HLA-G 3' UTR was genotyped as previously described (Tripathi et al., 2004). Briefly, after polymerase chain reaction (PCR), amplified products were size-discriminated by agarose gel electrophoresis with appropriate controls of known HLA-G genotypes that had previously been characterized by nucleotide sequencing. Alleles having the $14 \mathrm{bp}$ sequence in exon 8 was termed HLA-G 14pb Ins whereas those without, HLA-G 14pb Del.

\subsection{Statistical analysis}

Comparisons of genotype and allele frequencies between patients and controls were performed using the Chi-square testing with Yate's correction or Fisher exact test whenever appropriate. p values (two tailed) were corrected (pc) using the Bonferroni method and findings considered statistically significant for $p c$ equal or less than 0.05 . Odds Ratio (OR) and $95 \%$ confidence interval $(95 \% \mathrm{CI})$ were calculated to assess the relative risk conferred by a specific allele or genotype. The following demographic/clinical items i.e. age, gender, seasonality of birth, presence of thyroiditis, family history, suicidal behavior, violent suicide and polarity of the first episode were included in the analysis. Deviation from HardyWeinberg equilibrium was analyzed using $\chi^{2}$ testing. 


\section{Results}

Phenotype characteristics of patient and control groups are summarized in Table 1. For the studied polymorphism, the observed genotype distribution satisfied the expected Hardy Weinberg proportions for both patient and control samples and the overall frequencies were comparable to those previously published in public database (HLA-G 14bp Ins/Ins: 21\%, HLA-G 14bp Ins/Del: 48\% and HLA-G 14bp Del/Del: 31\% and HLA-G 14bp Ins/Ins: 22\%, HLA-G 14bp Ins/Del: 45\% and HLA-G 14bp Del/Del: $32 \%$ for patients and controls respectively) ( http://www.ncbi.nlm.nih.gov/).

We found that the HLA-G 14bp Ins allele was less represented in BD patients than in controls although failed to reach statistical significance (39\%vs $45 \%$ in patients and controls respectively, $p=0.07 ; \mathrm{OR}=0.79, \mathrm{CI95 \%}$ : 0.61-1.03) (Table 1). Nevertheless, analysis of the HLA-G 14bp genotype distribution revealed that the homozygous state of 14bp Ins allele was significantly more prevalent in healthy controls than in BD patients (HLA-G 14bp Ins/Ins vs other genotypes: $22 \%$ vs $14 \%, p=0.016, p c=0.032$; OR $=1.71,95 \% \mathrm{CI}=1.07-2.70)($ Fig. 1a and 1b). Analysis of HLA-G genotype distribution after stratification of patients based on their season of birth revealed that the prevalence of the HLA-G 14bp Ins/Ins genotype is less prevalent among patients born during the winter season than those born in other periods (HLAG 14bp Ins/Ins vs other genotypes: $6 \%$ vs $17 \%, p=0.003, p c=0.006$; OR $=3.16,95 \% \mathrm{CI}=$ 1.39 - 8.41) (Fig. 2). Concerning the other demographic/clinical variables, no significant association with HLA-G alleles/ genotypes was noted. 


\section{Discussion}

The underlying mechanisms in BD pathogenesis remain elusive albeit biological processes such as immune activation and immune suppression seems to parallel BD development and evolution (Figueireido and Mendes de Oliveira, 2011; Hamdani et al., 2012; Drexhage et al., 2011, Blume et al., 2010). Indeed manic and depressive episodes have been associated with both the Th1-mediated cellular and the Th2-mediated humoral pathways with the production of distinct pro-inflammatory cytokine profiles. In this context, HLA-G molecules, proven to be pivotal in immune tolerance through the induction of tolerogenic antigen presenting cells, Th2-type cytokines and regulatory $\mathrm{T}$ cells and through the inhibition of $\mathrm{T}$ cell proliferation, cytotoxic T lymphocyte-mediated lysis, NK cell proliferation and NK-mediated lysis (reviewed in Donadi et al., 2010) is of particular interest in the studies of immune dysfunction in BD.

To explore the immuno-genetic susceptibility factors in $\mathrm{BD}$, we studied a functionally relevant HLA-G gene polymorphism, namely the HLA-G 14bp Ins/Del variation. We found that the presence of the HLA-G 14bp Ins/Ins genotype, (and not the Ins allele), protects against the risk of developing $\mathrm{BD}$. This finding suggests that the protection conferred by the HLA-G 14bp Ins allele is dose dependant (recessive).

The 14-bp insertion allele, albeit generate more stable HLA-G mRNAs species (O'Brien et al., 2001, Rousseau et al., 2003, Hviid et al., 2003), had consistently been associated with low expression of HLA-G mRNA and low levels of serum sHLA-G (Chen et al., 2008, Rizzo et al., 2008). Such paradox in terms of stability and output is explained by the role of micro RNAs which by interacting with the HLA-G 3'mRNA region regulate the HLA-G phenotype expression (Veit and Chies, 2009, Castelli et al., 2010). Indeed, two polymorphic positions (rs 1063320 and $r s 9380142$ ) have been identified, the former as a binding site for micro RNAs with a role to down regulate HLA-G expression (Tan Z et al., 2007) and the latter associated 
with diminished stability of HLA-G mRNA species (Yie et al., 2008). Interestingly, these two variant alleles, affecting overall the HLA G protein expression, are found to be in strong linkage disequilibrium with the HLA-G 14bp Ins allele in various population groups (Castelli et al., 2010; Tan et al., 2007; Larsen et al., 2010).

Our data on the protective effect of the Ins/Ins genotype against BD risk fit perfectly within the concept that a downregulated expression of HLA-G molecules could moderate immunosuppressive/tolerogenic function with consequent improved protection against infectious challenges. Indeed low (associated with 14bp Ins allele) or absent (associated with HLA-G*0105N allele) HLA-G expression is protective against viral infections such as HTLV-1, human cytomegalovirus or hepatitis C and HIV (reviewed in Donadi et al., 2011). On the opposite, upregulation of the HLA-G expression has been shown to promote viral escape (Onno et al., 2000, Lozano et al., 2002). In fact, prenatal exposure to viruses with affinity for the Central Nervous System viz polio, rubella, herpes simplex type 2, cytomegalovirus or parasite such as $\mathrm{T}$ Gondii have previously been proposed as risk factors for psychosis (Dickerson et al., 2006, Niebuhr et al., 2008). Although the precise mechanistic relationship between $\mathrm{BD}$ and infectious events is less clear, the herpes virus type 1 had been associated with cognitive impairment (Dickerson et al., 2004), the Epstein - Barr virus (EBV) potentially with bipolar depression and the Borna Disease Virus inconsistently with mood disorders and BD (Ferszt et al., 1999, Terayama et al., 2003, Hornig et al., 2012) . Altogether, the hypothesis is that certain viral infections early in life initiate a cascade of biological events, irreversibly establishing a potential for dysregulated immune processes later in life and in particular in those genetically susceptible to BD. Two recent studies are in line with this hypothesis. In one study, the authors demonstrated that the genetic diversity of the cytotoxic $\mathrm{T}$ lymphocyte antigen 4 (CTLA4), a central molecule in the control of T-cell tolerance, confers risk both to recurrent schizophrenia, major depressive disorders and BD 
(Liu and al., 2011). In the other study, the authors showed that the percentages of antiinflammatory CD4(+) CD25(high) FoxP3+ regulatory $\mathrm{T}$ (Treg) cells, which are known to be induced by HLA-G (Yan., 2011), were higher in BD patients below 40 years of age as compared to healthy controls (Drexhage et al., 2011).

Although contested, excess number of Winter/Spring births had been noted among BD patients (Torrey et al., 1997; Tsuchiya et al., 2003). We found that the protective effect conferred by the low expressor HLA-G Ins/Ins genotype is observed mainly in patients born during the winter season, a seasonal window particularly rich in environmental infectious challenges (Moore et al., 2001). Based on this genetic association data we postulate that during this seasonal window, individuals bearing the low expressor HLA-G Ins/Ins genotype might benefit a better antiviral protection by their capacity to mount more efficient antiinfectious responses than those with other genotype combinations.

This observation could be also related to recent studies highlighting the role of human endogenous retrovirus-W (HERV-W) in the development of major psychosis including BD (Yolken et al., 2000, Frank et al. 2005, Weis et al., 2007). Representing a part of the human genome, the HERV-W elements vary across individuals in terms of copy number and chromosomal location (Griffiths et al., 2001) and can be triggered to express their antigens by a variety of environmental agents such as Influenza virus with potential seasonal infectious "risk" for BD during pregnancy. These elements may also be triggered later in life by Herpes viridae primary infections in young adulthood, or EBV or Herpes Simplex viruses (Nellaker et al., 2006, Perron et al., 1993). Such reactivation may correspond to the secondary boosting of HERV-W pathogenicity towards clinical disease after a long-term sub-clinical phase. This could explain why the various above-mentioned infectious agents behave as risk factors for BD. 
Overall, HLA-G polymorphism behaves as a biomarker for $\mathrm{BD}$ and further substratification of patients based on HLA G genotype and /or seasonality of birth may facilitate in identifying other biologic/genetic correlates of the biologically heterogeneous but currently clinically labeled as BD. To substantiate this, large trans-population studies are warranted. Such studies could help to recognize BD subtypes based on their biological/genetic profiles that can have significant impact on the patient subtype-based therapeutic approaches.

\section{Acknowledgments}

We thank bipolar patients and controls for their participation.

This work was supported by INSERM (UMRS 940 and U955), Assistance Publique des Hôpitaux de Paris, Agence Nationale pour la Recherche (ANR MNP2008 -VIP-Project), and the GIS NERF (grant to Monojit Debnath), Réseau Thématique de Recherche et de Soins en Santé Mentale (Fondation FondaMental®).

We thank the Cochin Hospital cell library (Dr J. Chelly), the Clinical Investigation Centre (Dr O. Montagne) and the Biological Resources Centre (Dr B. Galeh) of Mondor Hospital, and blood donor centre (Drs J.L. Beaumont and B. Mignen, EFS, Créteil) for technical assistance. 


\section{References}

A.P.A., 1994. Diagnostic and Statistical Manual of Mental Disorders, Fourth Edition. Masson, Paris.

Bainbridge, D.R., Ellis, S.A., Sargent, I.L., 2000. HLA-G suppresses proliferation of CD4(+) T-lymphocytes. J Reprod Immunol 48, 17-26.

Bech, P., Rafaelsen, O.J., Kramp, P., Bolwig, T.G., 1978. The mania rating scale: scale construction and interobserver agreement. Neuropharmacology 17, 430-431.

Blume, J., Douglas, S.D., Evans, D.L., 2011. Immune suppression and immune activation in depression. Brain Behav Immun 25, 221-229.

Boukouaci, W., Busson, M., Fortier, C., Amokrane, K., Peffault de Latour, R., Robin, M., Krishnamoorthy, R., Toubert, A., Charron, D., Socié, G., Tamouza, R., 2012. Association of HLA-G Low Expressor Genotype with SevereAcute Graft-versus-Host Disease after sibling Bone Marrow Transplantation. Front Alloimmunity and transplantation, in press.

Castelli, E.C., Mendes-Junior, C.T., Deghaide, N.H., de Albuquerque, R.S., Muniz, Y.C., Simões, R.T., Carosella, E.D., Moreau, P., Donadi, E.A., 2010. The genetic structure of 3'untranslated region of the HLA-G gene: polymorphisms and haplotypes. Genes Immun 11, 134-141.

Chen, X.Y., Yan, W.H., Lin, A., Xu, H.H., Zhang, J.G., Wang, X.X., 2008. The 14 bp deletion polymorphisms in HLA-G gene play an important role in the expression of soluble 
HLA-G in plasma. Tissue Antigens 72, 335-341.

Clerici, M., Arosio, B., Mundo., E, Cattaneo, E., Pozzoli, S., Dell'osso, B., Vergani, C., Trabattoni, D., Altamura, A.C., 2009. Cytokine polymorphisms in the pathophysiology of mood disorders. CNS Spectr 14, 419-425.

Collins, PY., Patel V., Joestl S.S., March D., Insel TR, Daar AS; Scientific Advisory Board and the Executive Committee of the Grand Challenges on Global Mental Health, Anderson W, Dhansay MA, Phillips A, Shurin S, Walport M, Ewart W, Savill SJ, Bordin IA, Costello EJ, Durkin M, Fairburn C, Glass RI, Hall W, Huang Y, Hyman SE, Jamison K, Kaaya S, Kapur S, Kleinman A, Ogunniyi A, Otero-Ojeda A, Poo MM, Ravindranath V, Sahakian BJ, Saxena S, Singer PA, Stein DJ., 2011. Grand challenges in global mental health. Nature 475, 27-30.

Czerski, P.M., Rybakowski, F., Kapelski, P., Rybakowski, J.K., Dmitrzak-Weglarz, M., Leszczyńska-Rodziewicz, A., Słopień, A., Skibińska, M., Kaczmarkiewicz-Fass, M., Hauser, J., 2008. Association of tumor necrosis factor $-308 \mathrm{G} / \mathrm{A}$ promoter polymorphism with schizophrenia and bipolar affective disorder in a Polish population. Neuropsychobiology 57, $88-94$.

Dickerson, F.B., Boronow, J.J., Stallings, C., Origoni, A.E., Cole, S., Krivogorsky, B., Yolken RH., 2004. Infection with herpes simplex virus type 1 is associated with cognitive deficits in bipolar disorder. Biol Psychiatry 55: 588-593. 
Dickerson, F., Kirkpatrick, B., Boronow, J., Stallings, C., Origoni, A., Yolken ,R., 2006. Deficit schizophrenia: association with serum antibodies to cytomegalovirus. Schizophr Bull, $32,396-400$.

Donadi, E.A., Castelli, E.C., Arnaiz-Villena, A., Roger, M., Rey, D., Moreau, P., 2011. Implications of the polymorphism of HLA-G on its function, regulation, evolution and disease association. Cell Mol Life Sci 68, 369-395.

Drexhage, R.C., Hoogenboezem, T.H., Versnel, M.A., Berghout, A., Nolen, W.A., Drexhage, H.A., 2011. The activation of monocyte and T cell networks in patients with bipolar disorder. Brain Behav Immun 25,1206-1213.

Eaton, W.W., Pedersen, M.G., Nielsen, P.R., Mortensen, P.B., 2010. Autoimmune diseases, bipolar disorder, and non-affective psychosis. Bipolar Disord 12, 638-646.

Farmer, A., Elkin, A., McGuffin, P., 2007. The genetics of bipolar affective disorder. Curr Opin Psychiatry 20, 8-12.

Ferszt, R., Severus, E., Bode, L., Brehm, M., Kühl, K.P., Berzewsk,i H., Ludwig, H., 1999. Activated Borna disease virus in affective disorders. Pharmacopsychiatry 32, 93-98.

Frank, O., Giehl, M., Zheng, C., Hehlmann, R., Leib-Mosch, C., Seifarth, W., 2005. Human endogenous retrovirus expression profiles in samples from brains of patients with schizophrenia and bipolar disorder. J Virol 79, 890-901. 
Figueiredo, T.C., de Oliveira, J.R., 2011. Reconsidering the Association Between the Major Histocompatibility Complex and Bipolar Disorder. J Mol Neurosci. Oct 11 [Epub ahead of print].

Goldstein, B.I., Kemp, D.E., Soczynska, J.K., McIntyre, R.S., 2009. Inflammation and the phenomenology, pathophysiology, comorbidity, and treatment of bipolar disorder: a systematic review of the literature. J Clin Psychiatry 70, 1078-1090.

Griffiths, D. J., 2001. Endogenous retroviruses in the human genome sequence. Genome Biol 2, REVIEWS1017.

Hamdani, N., Tamouza, R., Leboyer M., 2012. Immuno- inflammatory markers of bipolar disorder: a review of evidence. Front Biosci (Elite Ed) 4, 2170-82.

Hornig, M., Briese, T., Licinio, J., Khabbaz, R.F., Altshuler, L.L., Potkin ,S.G., Schwemmle, M., Siemetzki, U., Mintz, J., Honkavuori, K., Kraemer, H.C., Egan, M.F., Whybrow, P.C., Bunney, W.E., Lipkin, W.I., 2012. Absence of evidence for bornavirus infection in schizophrenia, bipolar disorder and major depressive disorder. Mol Psychiatry. 2012 Jan 31. doi: $10.1038 / \mathrm{mp} .2011 .179$

http://www.ncbi.nlm.nih.gov/

Hviid, T.V., Hylenius, S., Rørbye, C., Nielsen, L.G., 2003. HLA-G allelic variants are associated with differences in the HLA-G mRNA isoform profile and HLA-G mRNA levels. Immunogenetics 55, 63-79. 
IMGT/HLA Sequence Database: http://www.ebi.ac.uk/imgt/hla/

International Schizophrenia Consortium, Purcell S.M,. Wray N.R., Stone, J.L., Visscher , P.M., O'Donovan, M.C., Sullivan, P.F., Sklar, P., 2009. Common polygenic variation contributes to risk of schizophrenia and bipolar disorder. Nature 460, 748-752.

John, S.W., Weitzner, G., Rozen, R., Scriver, C.R. 1991., A rapid procedure for extracting genomic DNA from leukocytes. Nucleic Acids Res 19, 408.

Larsen, M.H., Hviid, T.V., 2009. Human leukocyte antigen-G polymorphism in relation to expression, function, and disease. Hum Immunol 70, 1026-1034.

Larsen, M.H., Hylenius, S., Andersen, A.M., Hviid, T.V., 2010. The 3'-untranslated region of the HLA-G gene in relation to pre-eclampsia: revisited. Tissue Antigens 75, 253-261.

Lichtenstein, P., Yip, B.H., Björk, C., Pawitan,Y., Cannon, T.D., Sullivan P.F., Hultman C.M., 2009. Common genetic determinants of schizophrenia and bipolar disorder in Swedish families: a population-based study. Lancet 373, 234-239.

Lozano, J.M., Gonzalez, R., Kindelan, J.M., Rouas-Freiss, N., Caballos, R., Dausset, J., Carosella, E.D., Pena, J., 2002. Monocytes and T lymphocytes in HIV-1-positive patients express HLA-G molecule. Aids 16, 347-351.

Maxwell, M.E., 1992. Manual for the Family Interview for Genetic Studies. NIMH. 
Montgomery, S.A., Asberg, M., 1979. A new depression scale designed to be sensitive to change. Br J Psychiatry134, 382-389.

Moore, P.B., El-Badri, S.M., Cousins, D., Shepherd, D.J., Young ,A.H., McAllister, V.L., Ferrier, I.N., 2001. White matter lesions and season of birth of patients with bipolar affective disorder. Am J Psychiatry 158, 1521-1524.

Nellaker, C., Yao, Y., Jones-Brando, L., Mallet F,., Yolken, R. H., Karlsson, H., 2006. Transactivation of elements in the human endogenous retrovirus $\mathrm{W}$ family by viral infection. Retrovirology 3, 44.

Niebuhr, D. W., Millikan, A. M., Cowan, D. N., Yolken, R., Li ,Y., Weber, N. S., 2008. Selected infectious agents and risk of schizophrenia among U.S. military personnel. Am J Psychiatry 165, 99-106.

Nurnberger, J.I. Jr., Blehar, M.C., Kaufmann, C.A., York-Cooler, C., Simpson, S.G., Harkavy-Friedman, J., Severe, J.B., Malaspina, D., Reich T., 1994. Diagnostic interview for genetic studies. Rationale, unique features, and training. NIMH Genetics Initiative. Arch Gen Psychiatry 51, 849-859 and 863-844.

O'Brien, M., McCarthy, T., Jenkins, D., Paul, P., Dausset, J., Carosella, E.D, . Moreau, P., 2001. Altered HLA-G transcription in pre-eclampsia is associated with allele specific inheritance: possible role of the HLA-G gene in susceptibility to the disease. Cell Mol Life Sci 58, 1943-1949. 
Onno, M., Pangault, C., Le Friec, G., Guilloux, V., Andre, P., Fauchet, R., 2000. Modulation of HLA-G antigens expression by human cytomegalovirus: specific induction in activated macrophages harboring human cytomegalovirus infection. J Immunol 164, 6426-6434.

Padmos, R.C., Bekris, L., Knijff, E.M., Tiemeier, H., Kupka, R.W., Cohen, D., Nolen, W.A., Lernmark, A., Drexhage, H.A., 2004. A high prevalence of organ-specific autoimmunity in patients with bipolar disorder. Biol Psychiatry 56, 476-482.

Paul, P., Cabestre, F.A., Ibrahim, E.C., Lefebvre, S., Khalil-Daher, I., Vazeux, G., Quiles, R.M., Bermond, F., Dausset, J., Carosella, E.D., 2000. Identification of HLA-G7 as a new splice variant of the HLA-G mRNA and expression of soluble HLA-G5, -G6, and -G7 transcripts in human transfected cells. Hum Immunol; 61, 1138-1149.

Perron, H., Suh, M., Lalande, B., Gratacap, B., Laurent, A., Stoebner, P., Seigneurin, J.M., 1993. Herpes simplex virus ICP0 and ICP4 immediate early proteins strongly enhance expression of a retrovirus harboured by a leptomeningeal cell line from a patient with multiple sclerosis. J Gen Virol 74, 65-72.

Rizzo, R., Hviid, T.V., Govoni, M., Padovan, M., Rubini, M, Melchiorri, L., Stignani, M., Carturan, S., Grappa, M.T., Fotinidi, M., Ferretti, S., Voss, A., Laustrup, H., Junker, P., Trotta, F., Baricordi, O.R., 2008. HLA-G genotype and HLA-G expression in systemic lupus erythematosus: HLA-G as a putative susceptibility gene in systemic lupus erythematosus. Tissue Antigens 71, 520-529.

Rouas-Freiss, N., Marchal, R.E., Kirszenbaum, M., Dausset, J., Carosella, E.D., 1997. The 
alpha1 domain of HLA-G1 and HLA-G2 inhibits cytotoxicity induced by natural killer cells: is HLA-G the public ligand for natural killer cell inhibitory receptors? Proc Natl Acad Sci USA 94, 5249-5254.

Rousseau, P., Le Discorde, M., Mouillot, G., Marcou, C., Carosella, E.D., Moreau, P., 2003. The $14 \mathrm{bp}$ deletion-insertion polymorphism in the 3' UT region of the HLA-G gene influences HLA-G mRNA stability. Hum Immunol 64, 1005-1010.

Serretti, A., Mandell,i L., 2008. The genetics of bipolar disorder: genome 'hot regions,' genes, new potential candidates and future directions. Mol Psychiatry 8, 742-771.

Tan, Z., Randall, G., Fan, J., Camoretti-Mercado, B., Brockman-Schneider, R., Pan, L., Solway, J., Gern JE,., Lemanske, R.F, . Nicolae, D., Ober, C., 2007. Allele-specific targeting of microRNAs to HLA-G and risk of asthma. Am. J. Hum. Genet 81, 829-834.

Taylor, L., Faraone, S.V, Tsuang, M.T., 2002. Family, twin, and adoption studies of bipolar disease. Curr Psychiatry Rep 4, 130-133.

Terayama, H., Nishino, Y., Kishi, M., Ikuta, K., Itoh, M., Iwahashi, K., 2003. Detection of anti-Borna Disease Virus (BDV) antibodies from patients with schizophrenia and mood disorders in Japan. Psychiatry Res 120, 201-206.

Torrey, E.F., Miller, J., Rawlings, R, Yolken, R.H., 1997. Seasonality of births in schizophrenia and bipolar disorder: a review of the literature. Schizophr Res 28,1-38. 
Tripathi, P., Abbas, A., Naik, S., Agrawal, S., 2004. Role of 14-bp deletion in the HLA-G gene in the maintenance of pregnancy, Tissue Antigens 64, 706-710.

Tsuchiya, K.J., Byrne, M., Mortensen, P.B., 2003. Risk factors in relation to an emergence of bipolar disorder: a systematic review. Bipolar Disord 5, 231-242.

Veit, T.D., Chies, J.A., 2009. Tolerance versus immune response -- microRNAs as important elements in the regulation of the HLA-G gene expression. Transpl Immunol 20, 229-231.

Vonk, R., van der Schot, A.C., Kahn, R.S., Nolen, W.A., Drexhage, H.A., 2007. Is autoimmune thyroiditis part of the genetic vulnerability (or an endophenotype) for bipolar disorder? Biol Psychiatry 62, 135-140.

Weis, S., Llenos, I. C., Sabunciyan, S., Dulay, J. R, Isler, L., Yolken, R., Perron, H., 2007. Reduced expression of human endogenous retrovirus (HERV)-W GAG protein in the cingulate gyrus and hippocampus in schizophrenia, bipolar disorder, and depression. J Neural Transm 114, 645-655.

Wiendl, H., Mitsdoerffer, M., Hofmeister, V., Wischhusen, J., Bornemann, A., Meyermann, R., Weiss, E.H., Melms, A., Weller, M., 2002. A functional role of HLA-G expression in human gliomas: an alternative strategy of immune escape. J Immunol 168, 4772-4780.

Yan, W.H., 2011. HLA-G expression in cancers: potential role in diagnosis, prognosis and therapy. Endocr Metab Immune Disord Drug Targets 11(1):76-89. 
Yie, S.M., Li, L.H., Xiao, R., Librach, C.L., 2008. A single base-pair mutation in the 3'untranslated region of HLA-G mRNA is associated with pre-eclampsia. Mol. Hum. Reprod. $14,649-653$.

Yolken, R., Karlsson, H., Yee, F., Johnston-Wilson, N.L., Torrey, E.F., 2000 Endogenous retroviruses and schizophrenia. Brain Res Brain Res Rev 31, 193-199. 


\section{Figure legends:}

\section{Figure 1a and 1b}

The homozygous state of $14 \mathrm{bp}$ Ins allele is significantly more prevalent in healthy controls than in bipolar disorder (BD) patients.

\section{Figure 2}

The HLA-G 14bp Ins/Ins genotype is less prevalent among patients born during the winter season than those born in other periods. 